\title{
Assessment of a Pharmacist-Led Direct Oral Anticoagulant Monitoring Clinic
}

\author{
Jenna Haché, Kwadwo Osei Bonsu, Rufaro Chitsike, Hai Nguyen, and Stephanie Young
}

Can J Hosp Pharm. 2021;74(1):7-14

\begin{abstract}
Background: Direct oral anticoagulants (DOACs) are recommended as first-line therapy for treatment and prevention of venous thromboembolism (VTE) and prevention of stroke related to nonvalvular atrial fibrillation. Recent publications have suggested incorporating DOAC monitoring into anticoagulant management clinics. The Eastern Health Adult Outpatient Thrombosis Service (Newfoundland and Labrador) includes a pharmacist-led DOAC monitoring clinic that uses standardized evidence-based care processes.
\end{abstract}

Objectives: To describe a new pharmacist-led DOAC monitoring clinic and to assess patients' adherence to medication therapy, adherence to guideline-recommended frequencies for blood work, and adverse and non-adverse events.

Methods: This retrospective chart review involved patients who attended their first visit to the DOAC clinic between October 10, 2017, and May 31, 2018. Patients were followed until November 30, 2018. Data were abstracted from electronic hospital records and the provincial pharmacy network. Descriptive statistics were used to analyze the data: categorical variables were presented as frequencies and percentages; continuous variables were analyzed and presented as means with standard deviations and, where applicable, as medians with interquartile ranges.

Results: Forty-seven patients, who attended a total of 74 clinic visits, were included. Twenty-eight patients $(60 \%)$ were adherent to their DOAC therapy. All patients had blood work completed before each clinic appointment. The mean time between the first and second sets of blood tests was 6.2 (standard deviation [SD] 1.4) months and between the second and third sets of blood tests was 5.1 (SD 1.0) months. There were no episodes of VTE or major bleeding. There was 1 cerebrovascular accident (3.2 events per 100 person-years, 95\% confidence interval [CI] 0.2-15.7) and 5 episodes of clinically relevant non-major bleeding ( 12.8 events per 100 person-years, $95 \% \mathrm{Cl} 4.1-30.1)$. Pharmacists identified 51 issues at the clinic appointments, of which 48 were medication-related. Referral to the Thrombosis Service physician was required to resolve $8(16 \%)$ of the issues identified. A brief discussion between the Thrombosis Service physician and pharmacist was required to resolve 30 (59\%) of the issues, with $13(25 \%)$ resolved by the pharmacist alone.

Conclusions: This study described the implementation and outcomes of a novel pharmacist-led DOAC clinic. Clinic patients underwent blood work at recommended intervals and received guidance on adherence and adverse events; as such, patients had follow-up that aligned with guideline recommendations.

Keywords: anticoagulant, direct oral anticoagulant, drug monitoring

\section{RÉSUMÉ}

Contexte : Les anticoagulants oraux directs (AOD) sont recommandés comme thérapie de première ligne pour le traitement et la prévention de la thromboembolie veineuse (TEV) et la prévention des AVC liés à la fibrillation auriculaire non valvulaire. Des publications récentes ont proposé d'incorporer le contrôle des AOD dans les cliniques des anticoagulants. L'Eastern Health Adult Outpatient Thrombosis Service (St John's, Terre-Neuve-et-Labrador) comprend une clinique de surveillance des AOD, dirigée par des pharmaciens qui utilisent des processus de soins standardisés basés sur des éléments de preuve.

Objectifs : Décrire une nouvelle clinique de surveillance des AOD dirigée par des pharmaciens et évaluer l'adhésion des patients à la pharmacothérapie, le respect de la fréquence des analyses sanguines recommandées dans les lignes directrices ainsi que les effets indésirables et ceux qui ne le sont pas.

Méthodes : Cet examen rétrospectif des dossiers impliquait des patients ayant effectué leur première visite à la clinique AOD entre le 10 octobre 2017 et le 31 mai 2018. Les patients étaient suivis jusqu'au 30 novembre 2018. Les données analysées provenaient de dossiers d'hospitalisation électroniques et du réseau des pharmacies provinciales. Des statistiques descriptives ont servi à analyser les données : les variables catégorielles ont été présentées sous forme de fréquences et de pourcentages; les variables continues ont été analysées et présentées sous forme de moyennes avec les écarts-types et, le cas échéant, sous forme de moyennes avec les écarts interquartiles.

Résultats : Quarante-sept patients, ayant effectué 74 visites en clinique, ont participé à l'étude. Vingt-huit patients $(60 \%)$ se conformaient à leur thérapie AOD. Les analyses sanguines de tous les patients ont été effectuées avant chaque rendez-vous en clinique. Le temps moyen entre le premier et le deuxième ensemble de tests sanguins était de 6,2 mois (écart-type standard [ET] 1,4), et de 5,1 mois (ET 1) entre le deuxième et le troisième. Aucun épisode de TEV ou d'hémorragie importante n'a eu lieu. II y a eu un accident cérébrovasculaire (3,2 événements par 100 années-personnes; intervalle de confiance $[I C]$ à $95 \% 0,2-15,7)$ et 5 épisodes de saignements non majeurs et cliniquement pertinents (12,8 événements par 100 annéespersonnes, IC $95 \% 4,1-30,1)$. Les pharmaciens ont décelé 51 problèmes lors des rendez-vous en clinique; parmi ceux-ci, 48 étaient liés aux médicaments. II a fallu faire appel au médecin du service des thromboses pour résoudre 8 (16\%) problèmes. Une brève discussion entre ce médecin et le pharmacien a été nécessaire pour résoudre 30 (59\%) problèmes et 13 (25\%) ont été réglés uniquement par le pharmacien.

Conclusions : Cette étude décrivait la mise en place et les résultats d'une nouvelle clinique $A O D$ dirigée par les pharmaciens. Les patients de la clinique ont subi une analyse sanguine aux intervalles recommandés et ont reçu des conseils sur l'adhésion et les effets indésirables; les patients ont donc bénéficié d'un suivi conforme aux lignes directrices.

Mots-clés : anticoagulant, anticoagulant oral direct, contrôle des médicaments 


\section{INTRODUCTION}

Anticoagulants are used to prevent and treat venous thromboembolism (VTE) and to reduce the risk of stroke in patients with nonvalvular atrial fibrillation. ${ }^{1,2}$ For decades, warfarin has been the main oral drug used for anticoagulation. However, the metabolism of warfarin varies among individuals, and many drug-drug interactions and drugdiet interactions can affect its safety and efficacy, leading to complications such as bleeding and thromboembolic events. ${ }^{3}$ Pharmacists have been successfully managing anticoagulant therapy, primarily warfarin, by leading specialized outpatient anticoagulation management services. A recent systematic review showed that pharmacist-managed outpatient anticoagulation services improve anticoagulation control, decrease bleeding and thromboembolic events, and decrease utilization of health care resources. ${ }^{4}$

Since 2009, four new oral anticoagulants have been introduced-apixaban, rivaroxaban, edoxaban, and dabigatran-which are collectively termed the direct oral anticoagulants (DOACs). ${ }^{3}$ The DOACs offer several advantages over warfarin, including more predictable dosing response, reduced need for frequent monitoring and dose adjustments, and fewer drug interactions. ${ }^{5}$ Because of these advantages, the DOACs have been recommended as firstline therapy for treatment and prevention of VTE, as well as for stroke prevention in patients with nonvalvular atrial fibrillation. ${ }^{6,7}$ This has resulted in an increase in the use of DOACs and a relative decline in the use of warfarin. ${ }^{8}$ The more predictable dosing response of DOACs has led many practitioners to believe that routine monitoring of DOACs is unnecessary. ${ }^{9}$ However, the DOACs are listed by the US Institute for Safe Medication Practices as high-risk medications and have been associated with a risk of serious adverse effects such as bleeding. ${ }^{10}$ In one study of 26471 patients with atrial fibrillation, less than $50 \%$ of patients were adherent to their DOAC therapy. ${ }^{11}$ It is therefore recommended that patients receive regular follow-up at 3- to 6-month intervals to enhance adherence and prevent adverse outcomes. ${ }^{1,9,12-14}$

Recent publications have suggested that DOAC monitoring should be incorporated into current anticoagulation clinics. ${ }^{3,9}$ Gladstone and others ${ }^{12}$ developed a checklist for anticoagulant monitoring based on the expert recommendations of the European Heart Rhythm Association. ${ }^{15}$ The checklist defines the following key categories of DOAC monitoring: A, for adherence; $\mathrm{B}$, for bleeding; $\mathrm{C}$, for creatinine clearance; $\mathrm{D}$, for drug interactions; $\mathrm{E}$, for examination; and F, for follow up. ${ }^{12}$ Despite extensive evidence showing the value of adding DOAC monitoring to pharmacist-led anticoagulation clinics, there are limited data concerning the implementation of this recommendation.

In October 2017, the Eastern Health Adult Outpatient Thrombosis Service became operational in one health region in Newfoundland and Labrador, Canada. The Thrombosis
Service is a comprehensive outpatient thrombosis and anticoagulation management program, which has integrated DOAC monitoring into the service model. The Thrombosis Service consists of several unique but interrelated clinics: an anticoagulation management clinic, a nonurgent thrombosis clinic, a perioperative anticoagulation management clinic, and an outpatient emergency thrombosis clinic. Within these clinics, a multidisciplinary team of thrombosis physicians/ hematologists and clinical pharmacists provide care through an evidence-based approach. ${ }^{2}$ The Thrombosis Service model utilizes pharmacists as the first point of patient contact.

In the present study, we aimed to describe a new pharmacist-led DOAC monitoring clinic and to assess outcomes for patients who attended the clinic, including adherence to medication therapy, adherence to guidelinerecommended frequencies for blood work, and occurrence of adverse and non-adverse events.

\section{METHODS}

We completed a retrospective chart review of the pharmacistled DOAC clinic at the Eastern Health Adult Outpatient Thrombosis Service. The study was approved by the Health Research Ethics Board through Eastern Health.

\section{Study Settings}

The pharmacist-led DOAC monitoring clinic, which is part of the Thrombosis Service, is held once weekly. One of the Thrombosis Service pharmacists, from the roster of 3 fulltime and 2 part-time pharmacists, is assigned to the clinic. Patients are referred to this clinic for long-term follow-up after it has been determined, during a separate Thrombosis Service clinic visit, that extended therapy with a DOAC is required. The DOAC clinic does not accept outside referrals at this time.

Patients are typically first seen within 6 months after referral, with follow-up planned to continue as long as DOAC therapy is required. The pharmacist determines the frequency of follow-up appointments (typically every 3-12 months). At each appointment, the pharmacist uses a standardized assessment tool, developed by the Thrombosis Service Team according to current evidence ${ }^{1,9,12-14}$ (and available upon request to the corresponding author), to assess the patient's status and the potential need for changes to therapy. During each clinic visit, the pharmacist works within the current scope of practice set out by the provincial pharmacy regulatory authority, interviewing the patient, assessing factors such as bleeding risk, thrombotic or bleeding events, and drug interactions, and determining whether the current DOAC dose continues to be appropriate for the patient. The pharmacist also assesses the patient's adherence to the prescribed therapy, assesses the patient for adverse effects, and completes special authorization request forms for the patient if needed. The pharmacist facilitates the 
completion of blood work requisitions by obtaining the signature of the Thrombosis Service physician after the requisitions have been prepared. The pharmacist is available for liaison with the patient's pharmacy and family physician as required. Clinic records are scanned and included in the patient's electronic health record. The pharmacist is able to consult the Thrombosis Service physician/hematologist regarding any issues that arise during patient interviews through a brief weekly discussion (approximately 15 minutes). Pharmacists at Eastern Health do not have collaborative practice agreements in place at this time; therefore, during these weekly discussions, the clinic pharmacist also asks the physician for new prescriptions for patients requiring medication changes. Additionally, based on these discussions and the pharmacist's recommendations, the physician decides whether the patient should have an in-person visit with the physician for further assessment.

\section{Participants}

All patients who attended their first visit (either scheduled or rebooked) at the DOAC clinic between October 10, 2017, and May 31, 2018, were eligible for inclusion (Figure 1). Patients were identified through electronic hospital records. Patients were excluded if they did not attend their scheduled appointment or if, upon presentation at a DOAC clinic visit, they were found to be receiving a low-molecularweight heparin or warfarin instead of a DOAC. We were unable to capture whether appointments were original or rebooked, because this information was removed from the system at some point before the time of chart review; however, patients who are not able to attend a given appointment are typically seen during the following clinic. The original study protocol specified that patients who met the inclusion criteria were to be followed until October 30, 2018; however, the follow-up period was later extended to November 30 , 2018, in an attempt to capture data for more than 1 clinic appointment for each participant.

\section{Data Collection}

Each patient was assigned a unique identifier. The principal investigator (J.H.) collected the data from electronic hospital records using a standardized data collection form. Data collected for the study included demographic characteristics, number of clinic visits, DOAC use, and indication for anticoagulation, as well as data related to prespecified outcomes. Data related to adverse events and blood work could

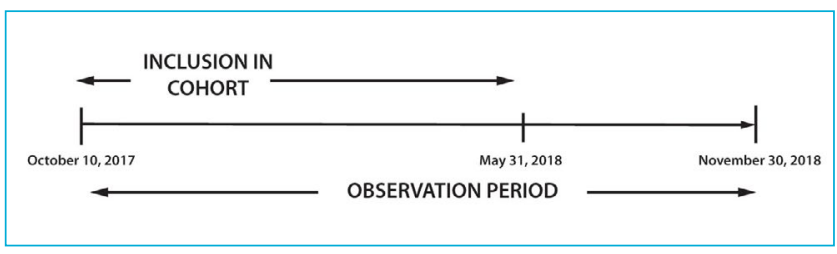

FIGURE 1. Timeline for the study. not be collected for patients residing outside the Eastern Health region. Medication refill data were provided by the Newfoundland and Labrador Centre for Health Information from the province's electronic Pharmacy Network database.

\section{Outcome Measures}

\section{Adherence}

A measure called the proportion of days covered (PDC) was used in determining patients' adherence to their DOAC therapy. The PDC was calculated by dividing the total number of days' supply dispensed during a specific patient's observation period by the total number of days in that patient's observation period and then multiplying by 100 ; the PDC was capped at $100 \% .{ }^{16}$ Medication adherence was defined as PDC of at least $80 \%$ and nonadherence as PDC less than $80 \% .{ }^{17-20}$ Adherence was calculated from each patient's first DOAC clinic appointment until October 30, 2018. This measure had an earlier end date than the remainder of the outcome data because the PDC data had to be submitted to the Newfoundland and Labrador Centre for Health Information according to the planned end date of the study (i.e., before the overall observation period of the study was extended). For patients admitted to hospital during the period of evaluation, days spent in hospital were excluded from the PDC calculation. Patients were excluded from this calculation if they had received physician samples of the medication, because the days' supply was not known for samples. Information on whether special authorization was required and completed was extracted and assessed from electronic hospital records.

\section{Follow-up Blood Work}

Dates and results of blood tests were obtained from each patient's medical records. The blood tests of interest were white blood cell count, serum creatinine (SCr) level, platelet count, mean corpuscular volume, hemoglobin, activated partial thromboplastin time, and international normalized ratio. These factors are commonly assessed in the monitoring of bleeding and renal function. SCr was used to calculate creatinine clearance $(\mathrm{ClCr})$ using the Cockcroft-Gault equation ${ }^{21}$ :

$\mathrm{ClCr}(\mathrm{mL} / \mathrm{min})$

$=\{[1.2 *(140-\text { age }) *(\text { weight in } \mathrm{kg})] / \mathrm{SCr}(\mu \mathrm{mol} / \mathrm{L})\}^{*} 0.85$ (if female $)$

We assessed the adherence to guideline-recommended frequencies of regular blood work and made note of the clinician who ordered the tests (Thrombosis Service physician or another physician). Clinic records were reviewed to determine whether any changes to patients' medication regimens were recommended on the basis of their blood test results.

\section{Adverse Events}

The number of adverse events experienced by each patient was extracted from hospital electronic records. Adverse events included hospital admissions or emergency department visits, 
VTE events, major bleeding events, and clinically relevant non-major bleeding events. VTE was defined by objective evidence of thrombosis on compression ultrasonography or venography of the leg veins and/or on ventilation-perfusion lung scanning, spiral computed tomography of the pulmonary arteries, or angiography. ${ }^{22}$ Bleeding events were defined according to definitions of the International Society on Thrombosis and Haemostasis. ${ }^{23}$ Major bleeding was defined as symptomatic presentation of bleeding and at least one of the following: fatal bleeding, bleeding in a critical area or organ (e.g., intra-articular, pericardial, intraocular, intraspinal), bleeding associated with a drop in hemoglobin of $20 \mathrm{~g} / \mathrm{L}$ or more, or requirement for transfusion of 2 or more units of whole blood or red cells. ${ }^{23}$ Clinically relevant non-major bleeding was defined as any sign or symptom of hemorrhage that did not fall into the category of major bleeding but did meet one of the following criteria: patient required medical intervention by a health professional, patient received a faceto-face evaluation, patient was admitted to hospital, or patient required an increase in level of care. ${ }^{23}$

\section{Non-adverse Events}

Changes to the medication regimen and medication-related issues identified by clinic staff were obtained from the clinic records. The medication-related issues identified were categorized as follows: nonadherence, dose too high, dose too low, needs additional therapy, unnecessary drug therapy, different drug needed, and adverse drug reaction (defined as a negative reaction to a drug product). ${ }^{24}$ For each medicationrelated issue identified, we assessed whether it was resolved by the pharmacist alone, through subsequent discussion with the Thrombosis Service physician, or through referral to the Thrombosis Service physician's clinic.

\section{Data Analysis}

No power calculation was completed because all patients receiving a $\mathrm{DOAC}$ and seen in the DOAC clinic during the specified time frame were included. Categorical variables are presented as frequencies and percentages and continuous variables as means with standard deviations (SDs) or medians and interquartile ranges. Adverse events data were analyzed descriptively as binary, count, and time-to-event variables.

\section{RESULTS}

\section{Patient Demographics}

A total of 47 patients were included in the study (Table 1). The most common DOAC used was rivaroxaban (30 patients [64\%]), and the most common indication for an anticoagulant was VTE (44 patients [94\%]). The mean follow-up time in the study was 9.1 (SD 2.0) months. All 47 patients had a first clinic visit, 24 patients (of 29 booked [83\%]) had a second clinic visit, and 3 patients (of 4 booked [75\%]) had a third clinic visit (Table 2). The mean time from the first clinic visit to the second clinic visit was 5.9 (SD 1.3) months, and the mean time between the second and third clinic visits was 5.5 (SD 1.8) months.

\section{Adherence}

Twenty-eight $(60 \%)$ of the patients were adherent to their DOAC therapy (i.e., PDC $\geq 80 \%$ ). The mean PDC was $79.6 \%$ (SD 20.3\%). The proportion of patients requiring special authorization for their DOAC declined with each clinic visit (21\% [10/47] for clinic visit $1,4.2 \%$ [1/24] for clinic visit 2 , and $0 \%[0 / 3]$ for clinic visit 3 ). However, the need for special authorization was largely unreported in the clinic records. Special authorization was completed at the first clinic appointment for 5 (11\%) of the 47 patients (Table 2). It is possible that patients documented as "requiring special authorization" for medication access might not have had the authorization completed by the DOAC clinic pharmacist because it had been completed before the clinic appointment.

\section{TABLE 1. Baseline Characteristics of Patients}

\begin{tabular}{|c|c|c|}
\hline Characteristic & \multicolumn{2}{|c|}{$\begin{array}{l}\text { No. (\%) of Patients }{ }^{\mathrm{a}} \\
\qquad(n=47)\end{array}$} \\
\hline Age (years) (mean \pm SD) & \multicolumn{2}{|c|}{$60.8 \pm 16$} \\
\hline $\begin{array}{l}\text { Sex } \\
\text { Male } \\
\text { Female }\end{array}$ & $\begin{array}{l}21 \\
26\end{array}$ & $\begin{array}{l}(45) \\
(55)\end{array}$ \\
\hline $\begin{array}{l}\text { DOAC } \\
\text { Apixaban } \\
\text { Dabigatran } \\
\text { Edoxaban } \\
\text { Rivaroxaban } \\
\text { Other }^{\text {b }}\end{array}$ & $\begin{array}{r}12 \\
2 \\
2 \\
30 \\
1\end{array}$ & $\begin{array}{r}(26) \\
(4) \\
(4) \\
(64) \\
(2)\end{array}$ \\
\hline $\begin{array}{l}\text { Indication for DOAC } \\
\text { Atrial fibrillation } \\
\text { Venous thromboembolism } \\
\text { Cerebral sinovenous thrombosis }\end{array}$ & $\begin{array}{r}2 \\
44 \\
1\end{array}$ & $\begin{array}{r}(4) \\
(94) \\
(2)\end{array}$ \\
\hline $\begin{array}{l}\text { Laboratory values at first visit }^{\mathrm{c}} \\
\mathrm{WBC}\left(\times 10^{9} \text { cells/L) (mean } \pm \mathrm{SD}\right) \\
\mathrm{CrCl}(\mathrm{mL} / \mathrm{min})(\text { mean } \pm \mathrm{SD}) \\
\text { Platelets }\left(\times 10^{9} \text { cells } / \mathrm{L}\right)(\text { mean } \pm \mathrm{SD}) \\
\text { Mean corpuscular volume }\left(\times 10^{-15} \mathrm{~L}\right)\end{array}$ & $\begin{array}{r}7 \\
89.8 \\
2 \\
92\end{array}$ & $\begin{aligned} & 2.4 \\
= & 38.77 \\
\pm & 58 \\
\pm & 5.9\end{aligned}$ \\
\hline $\begin{array}{l}\text { Hemoglobin (g/dL) (median and IQR) } \\
\text { aPTT (s) (median and IQR) } \\
\text { INR (median and IQR) }\end{array}$ & $\begin{array}{r}143.00 \\
32.35 \\
1.26\end{array}$ & $\begin{array}{l}\text { (IQR 24.00) } \\
\text { (IQR 6.32) } \\
\text { (IQR 0.34) }\end{array}$ \\
\hline
\end{tabular}

aPTT = activated partial thromboplastin time, $\mathrm{CrCl}=$ creatinine clearance, $\mathrm{DOAC}=$ direct oral anticoagulant, INR = international normalized ratio, IQR $=$ interquartile range, $\mathrm{SD}=$ standard deviation, $\mathrm{WBC}=$ white blood cells.

aExcept where indicated otherwise.

${ }^{b}$ One patient discontinued the DOAC on their own before attending the first DOAC clinic visit.

'Four patients were excluded from the analysis of laboratory values because their blood work was completed outside of the health authority where the study was conducted. 


\begin{tabular}{|c|c|c|c|c|c|c|}
\hline \multirow[b]{2}{*}{ Variable } & \multicolumn{6}{|c|}{ Clinic Visit; No. (\%) of Patients } \\
\hline & \multicolumn{2}{|c|}{ Visit $1(n=47)$} & \multicolumn{2}{|c|}{ Visit $2(n=24)$} & \multicolumn{2}{|c|}{ Visit $3(n=3)$} \\
\hline \multicolumn{7}{|l|}{ Medication insurance } \\
\hline No & 4 & (9) & 1 & (4) & 0 & $(0)$ \\
\hline Yes & 31 & (66) & 14 & (58) & 1 & (33) \\
\hline Not recorded & 11 & (23) & 8 & (33) & 2 & (67) \\
\hline Patient receiving samples & 1 & $(2)$ & 1 & (4) & 0 & $(0)$ \\
\hline \multicolumn{7}{|l|}{ Special authorization required } \\
\hline No & 31 & $(66)$ & 14 & $(58)$ & 2 & (67) \\
\hline Yes & 10 & $(21)$ & 1 & (4) & 0 & $(0)$ \\
\hline Not recorded & 6 & (13) & 9 & (38) & 1 & (33) \\
\hline \multicolumn{7}{|l|}{ Special authorization completed } \\
\hline No & 34 & $(72)$ & 15 & $(62)$ & 2 & (67) \\
\hline Yes & 5 & (11) & 0 & $(0)$ & 0 & (0) \\
\hline Not recorded & 8 & (17) & 9 & (38) & 1 & (33) \\
\hline
\end{tabular}

\section{Regular Blood Work}

The blood work analysis included data from 43 patients; the remaining 4 patients were excluded because they lived outside the health authority and subsequent blood work data could not be obtained. For all patients included in the analysis, scheduled blood work was completed before or shortly after each clinic appointment. The mean time between the first and second sets of blood tests was 6.2 (SD 1.4) months and between the second and third sets of blood tests was 5.1 (SD 1.0) months.

Most of the blood work was ordered by the Thrombosis Service physician, and most of the patients received the results at their clinic appointment. For the remaining patients, results were not available until after the clinic appointment, and there was no documentation as to how their results were communicated, given that telephone calls were not documented. Changes in laboratory values between clinic visits were not statistically significant during the period of observation and did not necessitate any changes to patients' medication regimens.

\section{Adverse Events}

During the observation period, there were no VTE events. There was 1 thromboembolic event, a cerebrovascular accident in a patient who was taking a DOAC for atrial fibrillation (overall rate 3.2 events per 100 person-years, 95\% confidence interval [CI] 0.2-15.7) (Table 3). In addition, there were 5 bleeding events, all of which were classified as clinically significant non-major bleeding (12.8 events per 100 person-years, 95\% CI 4.1-30.1). Of these 5 bleeding events, 2 occurred in the same patient. From the electronic hospital records available, 1 death was identified during the observation period, due to renal failure. We observed 17 hospital admissions and 45 emergency department visits. Only 1 (6\%) of the 17 hospital admissions was related to
TABLE 3. Adverse Outcomes during Observation Period ${ }^{\mathrm{a}}$

\begin{tabular}{|c|c|}
\hline Outcome & No. $(\%)^{b}$ \\
\hline No. of hospital admissions/patient & $n=43$ patients \\
\hline None & $34 \quad(79)$ \\
\hline 1 & (12) \\
\hline$\geq 2$ & (9) \\
\hline Reason for hospital admission & $n=17$ admissions \\
\hline Related to other thromboembolic events ${ }^{c}$ & $1 \quad(6)$ \\
\hline Unrelated to VTE or bleeding & $16 \quad(94)$ \\
\hline No. of ED visits/patient & $n=43$ patients \\
\hline None & $25 \quad(58)$ \\
\hline 1 & (14) \\
\hline$\geq 2$ & (28) \\
\hline Reason for ED visit & $n=45 \mathrm{ED}$ visits \\
\hline Related to other thromboembolic events ${ }^{c}$ & $1 \quad(2)$ \\
\hline Related to bleeding & (9) \\
\hline Unrelated to VTE or bleeding & $40 \quad(89)$ \\
\hline Other thromboembolic events ${ }^{c}$ & $\begin{array}{c}1 \text { (3.2 per } 100 \text { PYs, } \\
95 \% \text { Cl } 0.2-15.7)\end{array}$ \\
\hline \multicolumn{2}{|l|}{ Bleeding events $^{d}$} \\
\hline Major bleeding & 0 \\
\hline Clinically significant non-major bleeding & $\begin{array}{c}4 \text { (12.8 per } 100 \text { PYs, } \\
95 \% \text { Cl } 4.1-30.1)\end{array}$ \\
\hline
\end{tabular}

$\mathrm{Cl}=$ confidence interval, $\mathrm{ED}=$ emergency department, $\mathrm{PY}=$ person-year, $\mathrm{VTE}=$ venous thromboembolism.

aThe data in this table are based on 43 patients; 4 patients were excluded from the outcome analysis because they lived outside the health authority, and information on outcomes was not accessible through hospital records. bexcept where indicated otherwise.

"The single event in the category "other thromboembolic events" was an arterial event (specifically cerebrovascular accident) in a patient with atrial fibrillation and proportion of days covered less than $80 \%$. This event led to an ED visit, as well as hospital admission, and is included in the count for each of these outcomes.

${ }^{\mathrm{d}}$ There were 5 bleeding episodes in total; however, 2 of these episodes occurred in the same patient. For calculation of the frequency per $100 \mathrm{PYs}$, patients were excluded after their first event. Therefore, only 4 of the bleeding events were included in this calculation. 
a thromboembolic event. Of the 45 emergency department visits, $1(2 \%)$ was related to the cerebrovascular accident, and $4(9 \%)$ were related to bleeding (Table 3 ).

\section{Non-adverse events}

Many of the changes made to patients' medication regimens occurred at the first clinic visit. Of 47 patients, 7 (15\%) required changes to their medication regimens at their first appointment. The most common type of change was a dose change.

During the observation period, 51 issues were identified by the pharmacist (Table 4). Of these, 48 (94\%) were medication-related. The most common type of medicationrelated issue identified was an adverse drug reaction (35\%). About 25\% (13/51) of the issues identified were resolved by the pharmacist alone, whereas discussion with the Thrombosis Service physician was required to resolve 30 (59\%) of the issues, and referral to the clinic of the Thrombosis Service physician was required to resolve the remaining $8(16 \%)$ issues. The most common reason for referral was a potential adverse drug reaction $(38 \%[3 / 8])$.

\section{DISCUSSION}

Several studies have shown that patient education, monitoring, and long-term follow-up reduce nonadherence to medication therapy and improve anticoagulation management. ${ }^{25-28}$ Despite extensive evidence showing the value of adding DOAC monitoring to pharmacy-led anticoagulation clinics, few studies describing the implementation of this recommendation have been conducted. ${ }^{3,9,12}$

One study of 26471 patients with atrial fibrillation showed that less than $50 \%$ of the patients were adherent to their DOAC therapy. ${ }^{11}$ Recent publications have recommended that patients receive regular monitoring and follow-up at 3to 6-month intervals to enhance adherence and to prevent adverse outcomes. ${ }^{1,9,12-14}$ The patients at the Eastern Health pharmacist-led DOAC clinic received this recommended follow-up. However, we measured adherence in terms of the PDC, and the PDC calculation has many limitations; as such, we may have underestimated the level of adherence. For example, if a patient received a 90-day supply just before their first DOAC clinic appointment, those 90 days would not be counted in the calculation of PDC, which could lead to inaccurate representation of their adherence.

All patients in the current study had blood work completed for each clinic visit. The time between blood tests for patients with a second and possibly third set of laboratory tests during the observation period was 5-6 months. This interval is in line with recommendations for frequency of blood work for patients receiving long-term DOAC therapy. ${ }^{9} 15$ Recommendations for DOAC monitoring include assessing renal function every 3-12 months, depending on the patient's creatinine clearance. ${ }^{9,15}$ It has been shown that a decrease in estimated glomerular filtration rate is associated with an increase in risk of bleeding and thromboembolic events. ${ }^{29}$ Monitoring of renal function is especially important for patients who are taking a DOAC, because poor renal function may necessitate a dose reduction or a change in therapy. ${ }^{9}$ Patients were excluded from the major randomized clinical trials of DOACs if their creatinine clearance was less than $30 \mathrm{~mL} / \mathrm{min}$ ( $25 \mathrm{~mL} / \mathrm{min}$ for apixaban). ${ }^{30-33}$ Current product monographs for rivaroxaban and apixaban state that they can be used with caution in patients with creatinine clearance greater than $15 \mathrm{~mL} / \mathrm{min} .{ }^{34,35}$ One study compared

TABLE 4. Types of Real or Potential Drug Therapy Problems and Non-Drug-Related Issues Identified, Method of Resolution, and Proportion Leading to Change in the Medication Regimen

Method of Resolution; No. (\%) of Problems ${ }^{\mathrm{a}}$

\begin{tabular}{lcccccccccc} 
& Overall & \multicolumn{2}{c}{$\begin{array}{c}\text { Resolved by } \\
\text { Pharmacist }\end{array}$} & \multicolumn{2}{c}{$\begin{array}{c}\text { Discussed with } \\
\text { Physician }\end{array}$} & $\begin{array}{c}\text { Referral to } \\
\text { Physician }\end{array}$ & $\begin{array}{c}\text { Resulted in Change } \\
\text { to Medication }\end{array}$ \\
\hline No. of issues identified & 51 & $(100)$ & 13 & $(25)$ & 30 & $(59)$ & 8 & $(16)$ & 9 & $(18)$ \\
\hline Medication-related & 48 & $(94)$ & 13 & $(27)$ & 28 & $(58)$ & 7 & $(15)$ & 9 & $(19)$ \\
\hline Adverse drug reaction & 18 & $(35)$ & 10 & $(56)$ & 5 & $(28)$ & 3 & $(17)$ & 0 & $(0)$ \\
\hline Dose too high & 10 & $(20)$ & 0 & $(0)$ & 9 & $(90)$ & 1 & $(10)$ & 6 & $(60)$ \\
\hline Dose too low & 2 & $(4)$ & 0 & $(0)$ & 2 & $(100)$ & 0 & $(0)$ & 2 & $(100)$ \\
\hline Different drug needed & 4 & $(8)$ & 0 & $(0)$ & 3 & $(75)$ & 1 & $(25)$ & 1 & $(25)$ \\
Nonadherence & 13 & $(25)$ & 3 & $(23)$ & 8 & $(62)$ & 2 & $(15)$ & 0 & $(0)$ \\
\hline Unnecessary drug therapy & 1 & $(2)$ & 0 & $(0)$ & 1 & $(100)$ & 0 & $(0)$ & 0 & $(0)$ \\
\hline Not medication-related & 3 & $(6)$ & 0 & $(0)$ & 2 & $(67)$ & 1 & $(33)$ & 0 & $(0)$ \\
\hline
\end{tabular}

aFor the "Overall" column, percentages are calculated in relation to the total sample $(n=51)$. For all other columns, percentages are calculated in relation to number of issues for that row, as shown in the "Overall" column. 
the outcomes of patients treated with dabigatran followed by either a pharmacist-managed anticoagulant clinic or usual care and showed that the proportion of patients who underwent baseline laboratory testing before initiation of dabigatran was higher in the anticoagulant clinic group. This may indicate that pharmacists could improve patient monitoring by assessing laboratory values more closely. ${ }^{36}$

We found no episode of major bleeding during the period of observation in this study. However, our study was limited by a small sample size and short period of observation, and thus it was not powered for comparison with event rates reported in the literature. The stroke event in our study occurred in a patient with atrial fibrillation who had inadequate adherence to DOAC therapy.

The most common medication-related issue identified during the observation period was "adverse reaction". However, none of the adverse reactions led to a change in the medication regimen. The issues identified in the study were both real and potential, and upon further investigation, many of these issues were deemed unrelated to the DOAC. For adverse reactions deemed unrelated to the DOAC or the reason for their clinic visit, patients were referred to their primary care provider. Most of the changes to medication regimens made during clinic visits were decreases in dose, in accordance with recent evidence that a dose decrease may be recommended for some individuals meeting certain criteria. ${ }^{37,38}$ Of 51 issues identified, only $8(16 \%)$ required referral to the Thrombosis Service physician. The remainder of the issues were resolved by the pharmacist alone or through the brief weekly discussion with the physician. This provides a potential for savings of cost, as well as time, allowing the specialists to spend more time with patients who require more urgent care.

This study had a number of strengths. Given that little evidence is available on the implementation of a pharmacistled DOAC clinic, this study presents novel information not widely reported in the literature. Many variables have been described, providing a wide range of information about the pharmacist-led DOAC clinic. In particular, the proportion of patients receiving blood work regularly in pharmacist-led DOAC clinics has not previously been reported.

This study also had several limitations. It did not include a comparator group, which limits our ability to draw conclusions about causation and impact relative to usual care. Further studies should be conducted to compare variables such as adherence, regular blood work, and adverse events in a pharmacist-led DOAC clinic and in usual care (e.g., patients followed by their family physician). Another limitation is that the electronic health record does not contain information about patients' adverse event-related visits to their general practitioner or clinics outside the health authority. As such, our study did not include adverse events investigated in any setting outside the health authority. As mentioned above, there are limitations to the use of PDC in evaluating adherence. This method uses refill dates to estimate adherence and does not confirm actual drug consumption. The mean follow-up time was only 9 months, so patients with yearly follow-up had only one clinic visit during the course of the study. The study also had a relatively small sample size, likely because the intake period occurred during the first 7 months after the clinic was opened, when the number of patients being seen was still in the growth stage. VTE, stroke, and bleeding are rare events. Therefore, the confidence intervals for incidence rate estimates were wide. In the future, a larger study with a longer observation period would be beneficial to draw firmer conclusions.

\section{CONCLUSION}

The use of DOACs has been increasing rapidly since $2011 .^{8}$ It is recommended that patients taking DOACs undergo regular follow-up to improve adherence and decrease the rate of adverse events. This study has described the process for and results of implementation of a pharmacist-led DOAC clinic, which uses pharmacists as the first point of contact for regular follow-up of long-term anticoagulation. Patients being followed in this clinic had blood work performed at guideline-recommended frequencies. ${ }^{9,11,15,28}$ Although 1 patient experienced a cerebrovascular accident, no patients experienced major bleeding or VTE. This model for DOAC management provides patients with high-quality follow-up that aligns with guideline recommendations. This descriptive study can be used by clinicians as a guide to initiating similar clinics within their own institutions.

\section{References}

1. Steffel J, Verhamme P, Potpara TS, Albaladejo P, Antz M, Desteghe L, et al. The 2018 European Heart Rhythm Association practical guide on the use of non-vitamin $\mathrm{K}$ antagonist oral anticoagulants in patients with atrial fibrillation. Eur Heart J. 2018;39(16):1330-93.

2. Kearon C, Akl EA, Ornelas J, Blaivas A, Jimenez D, Bounameau H, et al Antithrombotic therapy for VTE disease. Chest. 2016;149(2):315-52.

3. Barnes GD, Nallamothu BK, Sales AE, Froehlich JB. Reimagining anticoagulation clinics in the era of direct oral anticoagulants. Circ Cardiovasc Qual Outcomes. 2016;9(2):182-5.

4. Manzoor BS, Cheng WH, Lee JC, Uppuluri EM, Nutescu EA Quality of pharmacist-managed anticoagulation therapy in longterm ambulatory settings: a systematic review. Ann Pharmacother. 2017;51(12):1122-37.

5. Baglin T. Clinical use of new oral anticoagulant drugs: dabigatran and rivaroxaban. Br J Haematol. 2013;163(2):160-7.

6. Kearon C, Akl EA, Comerota AJ, Prandoni P, Bounameaux H, Goldhaber S, et al. Antithrombotic therapy for VTE disease. Chest. 2012;141(2):e419S-e496S.

7. Macle L, Cairns J, Leblanc K, Tsang T, Skanes A, Cox J, et al. 2016 Focused update of the Canadian Cardiovascular Society guidelines for the management of atrial fibrillation. Can J Cardiol. 2016;32(10):1170-85.

8. Weitz JI, Semchuk W, Turpie AGG, Fisher WD, Kong C, Ciaccia A, et al. Trends in prescribing oral anticoagulants in Canada, 2008-2014. Clin Ther. 2015;37(11):2506-2514.e4.

9. Mohammad I, Korkis B, Garwood CL. Incorporating comprehensive management of direct oral anticoagulants into anticoagulation clinics. Pharmacotherapy. 2017;37(10):1284-97. 
10. Annual report issue - July 2017. In: QuarterWatch reports. Institute for Safe Medication Practices (US); 2017 [cited 2019 Jul 18]. Available from: https://www.ismp.org/quarterwatch/annual-report-2016

11. Yao X, Abraham NS, Alexander GC, Crown W, Montori VM, Sangaralingham LR, et al. Effect of adherence to oral anticoagulants on risk of stroke and major bleeding among patients with atrial fibrillation. J Am Heart Assoc. 2016;5(2):e003074.

12. Gladstone DJ, Geerts WH, Douketis J, Ivers N, Healey JS, Leblanc K. How to monitor patients receiving direct oral anticoagulants for stroke prevention in atrial fibrillation: a practice tool endorsed by Thrombosis Canada, the Canadian Stroke Consortium, the Canadian Cardiovascular Pharmacists Network, and the Canadian Cardiovascular Society. Ann Intern Med. 2015;163(5):382-5.

13. Sylvester KW, Ting C, Lewin A, Collins P, Fanikos J, Goldhaber SZ, et al. Expanding anticoagulation management services to include direct oral anticoagulants. J Thromb Thrombolysis. 2018;45(2):274-80.

14. Leblanc K, Semchuk WM, Papastergiou J, Snow B, Mandlsohn L, Kapoor V, et al. A pharmacist checklist for direct oral anticoagulant management: raising the bar. Can Pharm J. 2018;151(2):102-6.

15. Heidbuchel H, Verhamme P, Alings M, Antz M, Diener HC, Hacke W. Updated European Heart Rhythm Association practical guide on the use of non-vitamin-K antagonist anticoagulants in patients with non-valvular atrial fibrillation: executive summary. Eur Heart J. 2017;38(27):2137-49.

16. Raebel MA, Schmittdiel J, Karter AJ, Konieczny JL, Steiner JF. Standardizing terminology and definitions of medication adherence and persistence in research employing electronic databases. Med Care. 2013;51(8 Suppl 3):S11-21.

17. Benner JS, Glynn RJ, Mogun H, Neumann PJ, Weinstein MC, Avorn $\mathrm{J}$. Long-term persistence in use of statin therapy in elderly patients. JAMA. 2002;288(4):455-61.

18. Connolly SJ, Ezekowitz MD, Yusuf S, Eikelboom J, Oldgren J, Parekh A, et al. Dabigatran versus warfarin in patients with atrial fibrillation. N Engl J Med. 2009;361(12):1139-51.

19. Gorst-Rasmussen A, Skjøth F, Larsen TB, Rasmussen LH, Lip GYH, Lane DA. Dabigatran adherence in atrial fibrillation patients during the first year after diagnosis: a nationwide cohort study. $J$ Thromb Haemostasis. 2015;13(4):495-504.

20. Shore S, Carey EP, Turakhia MP, Jackevicius CA, Cunningham F, Pilote L, et al. Adherence to dabigatran therapy and longitudinal patient outcomes: insights from the Veterans Health Administration. Am Heart J. 2014;167(6):810-7.

21. Calculations and dosing tools. In: Compendium of pharmaceuticals and specialties. Canadian Pharmacists Association; 2015. p. L3.

22. Schulman S, Kearon C, Kakkar AK, Mismetti P, Schellong S, Eriksson $\mathrm{H}$, et al. Dabigatran versus warfarin in the treatment of acute venous thromboembolism. N Engl J Med. 2009;361(24):2342-52.

23. Kaatz S, Ahmad D, Spyropoulos AC, Schulman S. Definition of clinically relevant non-major bleeding in studies of anticoagulants in atrial fibrillation and venous thromboembolic disease in non-surgical patients: communication from the SSC of the ISTH. J Thromb Haemostasis. 2015;13(11):2119-26.

24. Cipolle RJ, Strand L, Morley P. Pharmaceutical care practice: the patient centered approach to medication management. 3rd ed. McGraw-Hill; 2012.

25. Murray MD, Young J, Hoke S, Tu W, Weiner M, Morrow D, et al. Pharmacist intervention to improve medication adherence in heart failure: a randomized trial. Ann Intern Med. 2007;146(10):714-25.

26. Weinstein AG. The potential of asthma adherence management to enhance asthma guidelines. Ann Allergy Asthma Immunol.2011;106(4): 283-91.

27. Garrett DG, Bluml BM. Patient self-management program for diabetes: first-year clinical, humanistic, and economic outcomes. J Am Pharm Assoc. 2005;45(2):130-7.

28. Haynes RB, Yao X, Degani A, Kripalani S, Garg A, McDonald HP. Interventions to enhance medication adherence. Cochrane Database Syst Rev. 2005;(4):CD000011.

29. Roldán V, Marín F, Fernández H, Manzano-Fernandez S, Gallego P, Valdés M, et al. Renal impairment in a "real-life" cohort of anticoagulated patients with atrial fibrillation (implications for thromboembolism and bleeding). Am J Cardiol. 2013;111(8):1159-64.

30. Camm AJ. The RE-LY study: randomized evaluation of long-term anticoagulant therapy: dabigatran vs. warfarin. Eur Heart J. 2009;30(21) 2554-5.

31. Granger CB, Alexander JH, McMurray JJV, Lopes RD, Hylek E, Hanna $\mathrm{M}$, et al. Apixaban versus warfarin in patients with atrial fibrillation. N Engl J Med. 2011;365(11):981-92.

32. Patel MR, Mahaffey KW, Garg J, Pan G, Singer DE, Hacke W, et al. Rivaroxaban versus warfarin in nonvalvular atrial fibrillation. $N$ Engl Med. 2011;365(10):883-91.

33. Giugliano RP, Ruff CT, Braunwald E, Murphy S, Wivitt SD, Halperin $\mathrm{JL}$, et al. Edoxaban versus warfarin in patients with atrial fibrillation. N Engl J Med. 2013;369(22):2093-104.

34. Xarelto ${ }^{\infty}$ [product monograph]. Bayer Inc; 2018 Sep 18

35. Eliquis ${ }^{\circ}$ [product monograph]. Bristol-Myers Squibb Canada Co; 2019 Mar 12.

36. Lee PY, Han SY, Miyahara RK. Adherence and outcomes of patients treated with dabigatran: pharmacist-managed anticoagulation clinic versus usual care. Am J Health Syst Pharm. 2013;70(13):1154-61.

37. Agnelli G, Buller HR, Cohen A, Curto M, Gallus AS, Johnson M, et al. Apixaban for extended treatment of venous thromboembolism. N Engl J Med. 2013;368(8):699-708.

38. Weitz JI, Lensing AWA, Prins MH, Bauersachs R, Beyer-Westendorf J, Bounameaux $\mathrm{H}$, et al. Rivaroxaban or aspirin for extended treatment of venous thromboembolism. N Engl J Med. 2017;376(13):1211-22.

Jenna Haché, BSc(Biochem), BSc(Pharm), RPh, is with Eastern Health and with the School of Pharmacy, Memorial University of Newfoundland and Labrador, St John's, Newfoundland and Labrador.

Kwadwo Osei Bonsu, BSc(Pharm), PhD, is with the School of Pharmacy, Memorial University of Newfoundland and Labrador, St John's, Newfoundland and Labrador.

Rufaro Chitsike, MD, MMed(Haem), is with Eastern Health and with the School of Pharmacy, Memorial University of Newfoundland and Labrador, St John's, Newfoundland and Labrador.

Hai Nguyen, PhD, is with the School of Pharmacy, Memorial University of Newfoundland and Labrador, St John's, Newfoundland and Labrador.

Stephanie Young, BSc(Pharm), ACPR, PharmD, MSc(Med), is with Eastern Health and with the School of Pharmacy, Memorial University of Newfoundland and Labrador, St John's, Newfoundland and Labrador.

Competing interests: For activities outside the work presented here, Rufaro Chitsike and Stephanie Young have received grants from Bayer. No other competing interests were declared.

Address correspondence to:

Jenna Hache

MUN School of Pharmacy

300 Prince Philip Drive

St John's NL A1B 3V6

email: Jenna.hache@easternhealth.ca

Funding: The development, implementation, and evaluation of the Thrombosis Service, including this study, was supported by an unrestricted grant from Sanofi Canada. 